\title{
Econometric Analysis of Dairy Farmer's Access to Agricultural Information in Ada'A District
}

\author{
Adi Kelil $^{1} \quad$ Yohannes Girma $^{2}$ \\ 1. Department of Agricultural Economics, Jinka University \\ 2. Department of Agricultural Economics, Injibara University
}

\begin{abstract}
This study set out to analyze the determinants of Dairy Farmer's access to agricultural information in Ada'a District, East Shoa Zone, Central Ethiopia. A three-stage sampling procedure was employed in which both non-probability sampling for the study area and probability sampling procedures were followed to select the three kebele and 136 respondents. The binary logit model analysis result revealed that sex, education level, social participation, extension contact, credit access, and innovation proneness have significant and positive influence on access to Agricultural information, where as age of household head has significant negative influence on Dairy farmer's access to Agricultural information at different significant levels. Therefore, focus ought to be given regarding Gender difference; improving literacy rate, increasing extension worker and creating strong linkage with financial organizations to foster provision of credit service for farmer are strongly recommended to enhance agricultural Development through increasing provision of agricultural information.
\end{abstract}

Keywords: access, Agricultural information, Dairy farmer, Binary logit

DOI: $10.7176 / \mathrm{JESD} / 12-19-02$

Publication date:October $31^{\text {st }} 2021$

\section{INTRODUCTION}

Africa is the continent where the economy's backbone is agriculture and where the largest percentages of people are poor farmers. About two-thirds of the population in Africa, especially in sub-Saharan Africa and about $72 \%$ of those in East Africa are dependent on agriculture for their livelihoods (Adekunle et al., 2012). Ethiopia is known for its large livestock population in Africa, with 58 million cattle, 24 million goats, 27 million sheep, and 49 million chickens (CSA, 2015). The dairy sector contributes considerably to the national Gross Domestic Product (GDP) with annual milk production estimated about 3.8 billion liters from cattle and 165 million liters from camel (CSA, 2013).

Rapid growth of population, low agricultural production and productivity are major problems faced by the country. Consequently, these result wide gaps between potential demands of the growing population of Ethiopia. To meet the demand of fast growing population, dairy production level has to grow at rate of 4 percent per annum (Yilma et al., 2011). Hence, the government planned to almost double domestic milk production between 2015 and 2020(Zijlstra et al., 2015).

Agricultural sectors are increasingly becoming knowledge intensive. Researchers from local to global levels continue to generate new information. Yet as agriculture systems become more complex, farmers' access to a reliable, meaningful, timely and relevant information source is critical to farmers' in addition to being packaged and delivered in a way preferred by them (Babu et al., 2012). Agricultural knowledge and information are the key components in commercial smallholder dairy development. it play a significant role in improving productivity, linking producers to remunerative markets, improving competitiveness in markets, and thus leading to improved livelihood, food security and national economies (Oladele, 2011).

Dairy farmers in Ethiopia do have problems in accessing agricultural information from extension service and other sources. Such problems among rural farmers could be related to various personal, social, economical, psychological and institutional factors. Hence, to analyze the determinants of Dairy Farmer's in accessing agricultural information is essential to identify the gaps in accessing agricultural information in the research area. Therefore, this study is expected to fill such gap existed in the area for a period by contributing insights and implications for intervention.

\section{MATERIALS AND METHODS}

The study was conducted in Ada'a District, East shoa zone, Central Ethiopia. A multi stage sampling technique was adopted to select the sample respondents in the proposed study. In the first stage, Ada'a District was selected purposely based on potential smallholder dairy production and larger number of dairy cattle population place. In the second stage, the District was stratified into urban, peri-urban and rural areas. Then, one kebele from each stratum was selected randomly. Finally, 136 sample households were selected randomly based on probability proportional to sample size.

The data were collected based on the Explanatory variables which were hypothesized to determine the accessibility of Agricultural information. These independent variables include demographic, socio-economical, 
Psychological and Institutional factors.

\section{Econometric Model Specification}

For the purpose of this study, logit model was employed to assess the Determinants' on accessing agricultural information. The reason logit model chosen than others is as follows:

Several statistical models can be employed to depict the association between factors and access of agricultural information. In information access studies, responses to a question such as whether farmers access agricultural information could be 'yes' or 'no', a typical indication of dichotomous variable. The common approaches to estimating such dichotomous variable are logit Model, probit models and linear probability models (Gujarati, 1995).

The linear probability model has defect since it may generate predicted values outside the $0-1$ intervals, which violates the basic logic of probability. The other problem with LPM is that the variance of the disturbance term is heteroscedastic. Furthermore, the assumption of normality in the disturbance term is no longer tenable (Maddala, 1983). Due to the defects of the linear probability model, Logit and probit Models are the convenient functional forms for models with binary endogenous variable (Amemiya, 1981).

In most case probit and Logit model outcome is similar. The choice between these two models depends on practical concerns such as the availability and flexibility and experience.

Logistic model has leverage over others in the analysis of Binary outcome variables in that it lends itself to a meaningful interpretation from a mechanical view point, and simpler in estimation than the probit model and flexible character (Pindyck and Rubinfeld, 1981). Therefore, in this study a binary logit regression model will be employed to set out the determinants of Dairy Farmer's in accessing agricultural information.

\section{Binary Logit Model}

Following Guajarati (1995) the functional form of logit model is specified as follows:

$$
p_{i}=E\left(Y=\frac{1}{X_{I}}\right)=\frac{1}{1+e^{-\left(B_{0}+B_{i} X_{i}\right)}}
$$

For ease of expositions, we write (1) as;

$$
P_{i}=\frac{1}{1+e^{-Z_{i}}}
$$

The probability that a given households access agricultural information are expressed by (2) while, the probability for non access agricultural information is given by:

$$
1-P_{i}=\frac{1}{1+e^{Z_{i}}}
$$

Therefore we can write:

$$
\frac{P_{i}}{1-P_{i}}=\frac{1+e^{z_{i}}}{1+e^{-Z_{i}}}
$$

Now $\left(P_{i} / 1-P_{i}\right)$ issimply the odds ratio in favor of being accessed agricultural information. i.e. The ratio of the probability of accessing agricultural information to that of the probability of non accessing it.

Finally taking the natural logarithms of equations (4) we obtained:

$$
L_{i}=\ln \left(\frac{P_{i}}{1-P_{i}}\right)=Z_{i}=\beta_{0}+\beta_{1} X_{1}+\beta_{2} X_{2}+---+\beta_{n} X_{n}
$$

Where $\mathrm{P}_{i}$ is probability of accessing agricultural information that ranges from 0 to 1 and $\mathrm{Zi}$ is a function of $\mathrm{n}$ independent variables $(\mathrm{X} i)$ which can be expressed as:

$$
Z_{i}=\beta_{0}+\beta_{1} X_{1}+\beta_{2} X_{2}+--+\beta_{n} X_{n}
$$

Where $B_{0}$ is intercept, $B 2$, ----, $B_{n}$ are the slope parameters in the model $\mathrm{L}_{i}=$ is the $\log$ of the odds ratio, which is not only linear in $X$ but also linear in parameters. $X_{i}$ is vector of the relevant sampled household's characteristics. If the disturbances term $\left(\mathrm{U}_{i}\right)$ is introduced to the logit model it becomes:

$$
Z_{i}=\beta_{1}+\beta_{1} X_{1}+\beta_{1} X_{2}+---\beta_{n} X_{n}+U_{i}
$$

Prior to running the Logit model, the presence or absence of multicoliniarity was checked. According to Gujarati (1995) there are two measures that are often suggested to test the existence of mulitcollineality. These are: Variance Inflation Factor (VIF) for association among the continuous explanatory variables and contingency coefficients for dummy variables.

VIF (Variance inflation factor) values were then calculated for the independent variables to check for multicoliniarity, and since none was found to be above 10, the regression results were accepted. Likewise, to check multicolinearity of dummy and categorical variables, contingency coefficient (C.C) was employed. Contingency coefficient value ranges between zero and one, where zero indicates no association between the variables and value close to one indicates high degree of association between the independent variables. As a general rule, if the $\mathrm{CC}$ of a variable exceeds 0.75, there is multicolinearity. As is indicated in Appendix 1, there was no multicolinearity effect observed within the variables.

The result of the correlation coefficient reveals the absence of multicolinearity or high degree of association problem among independent variables. Hence, there was no explanatory variable dropped from the estimated model since no serious problem of multicolinearity was detected. 
The Binary logit model was employed for the purpose of significant explanatory and independent variables put in to ordered logit model to screen out important factors which determine the accessibility of agricultural information in the study area. The results of this study confirm that access of agricultural information was determine by the simultaneous interaction of several personal, Demographic, socio-economic, psychological and institutional factors. Of the total 14 explanatory variables included in the regression, seven had a significant association with access to dairy information. Sex of household head, educational status of the household head, Social participation of the household head, access to credit, extension contact and innovation proneness influenced access to dairy information positively, while Age of the household head influenced negatively. For ease of interpretation, marginal effects were computed for each outcome in the dependent variable (Table 1.1).

RESULT OF THE ECONOMETRIC MODEL

Table .1.1 logistic regression model output

\begin{tabular}{llllll}
\hline Variables & Coef. & Std. Err. & $\mathrm{Z}$ & $\mathrm{P}>|\mathrm{Z}|$ & Marginal Effect $(\mathrm{dy} / \mathrm{dx})$ \\
\hline AGEHH & -0.062 & 0.024 & -2.62 & 0.009 & $-0.01058^{* * *}$ \\
SEXHH & 2.932 & 1.009 & 2.91 & 0.004 & $0.580625^{* * *}$ \\
HHSIZE & 0.97 & 0.123 & 0.78 & 0.433 & 0.016503 \\
EDULHH & 0.315 & 0.145 & 2.17 & 0.030 & $0.053808^{* *}$ \\
OFFI & -0.048 & 0.436 & -1.12 & 0.261 & -0.008246 \\
EXTCON & 0.077 & 0.31 & 2.48 & 0.013 & $0.013069^{* *}$ \\
MKTD & -0.065 & 0.291 & -0.22 & 0.822 & -0.011139 \\
SPART & 1.996 & 0.870 & 2.29 & 0.022 & $0.391074^{* *}$ \\
ACCREDIT & 2.112 & 0.838 & 2.52 & 0.012 & $0.364650^{* *}$ \\
LIVOW & 0.568 & 0.966 & 0.59 & 0.557 & 0.096987 \\
INFOSEEK & 0.051 & 0.060 & 0.85 & 0.395 & 0.00874 \\
IPRO & 0.265 & 0.146 & 1.82 & 0.069 & $0.045216^{*}$ \\
MMEXPO & 0.106 & 0.143 & 0.74 & 0.459 & 0.018083 \\
LANDSIZE & 0.091 & 0.444 & 0.21 & 0.837 & 0.015580 \\
Number of obs $=136$ & 136 & LR chi2 $(15)=$ & 127.55 & \\
Prob $>$ chi2 $=$ & 0.0000 & Pseudo R2 $=0.6950$ &
\end{tabular}

Log likelihood $=-27.991694$

Source: survey data model output, 2017 . Note: $* * *, * *$ and $*$ denotes significance at $1 \%, 5 \%$ and $10 \%$ probability level respectively.

\section{DISCUSSION}

Age: The Binary Logit model output shows that age of household head was negatively associated with dairy information at $1 \%$ significance level. The possible explanation of this result is that the young farmers are keen to acquire knowledge and information than older farmers and older farmers do not have the interest to participate in an activity that requires much time and energy. Older men are less likely to engage in simultaneous receiving and providing of information, perhaps due to the low ability to communicate associated with old age (Katungi, 2006). In similar vein, Bekele (2008) reveals that increase in age would have negative influence in accessing agricultural information.

Sex: As the logit model result indicates, the variable sex had a significant influence on access to dairy information at $1 \%$ significance level. All other things being held constant, the probability of dairy information access of male -headed household increase by $58.06 \%$ compared to female-headed households. This indicates that being male and female make a significant difference in accessing dairy information. The probable reason of this result is that due to many socio-cultural values and norms, males have freedom of mobility, participation in different meetings and engagement in more dispersed social networks, thus giving them a greater chance to access information. However, women's have multiple responsibilities in side their houses, which limits the possibility of their exposure to external environment and the chance of obtaining dairy information. Their accessibility to dairy information is mainly based on their everyday interactions with the groups of individuals with whom they regularly come into contact.

This is consistent with a priori expectation and the findings of previously conducted studies. study conducted by Geleta (2015) reveal that access score to agricultural information significantly and positively in favor of men. According to Habtemariam (2004), male-headed households are said to have better access to agricultural information than female-headed households, which is attributed to negatively influence of cultural norms and traditions. Similarly, a study conducted by Pipy, (2006), on poultry Farmers' Utilization of Information in Lagelu Local Government Area of Nigeria reveals that, there was significant difference between male and female headed households in poultry production information source and utilization.

Education Level of household heads (EDULHH): The formal year of schooling has positive relationship with 
access to dairy information at 5\% significance level. The model result indicated that all other factors remaining constant, the probability of access to dairy information increases by $5.38 \%$ for each additional year of education. This shows that the educated farmers are more likely to access dairy information than those who are not educated. The probable reason for this result is that formal education enhances the ability to understand, derive, analyze, decode and evaluate relevant information for agricultural production.

The finding of this study is in line with many of the previously conducted studies. Study conducted by Rehman (2013) indicate that there existed a highly significant relationship between education of the respondents and their access to agricultural information and also denoted that with the increase in the educational level of the respondents, there was an increase in their access to agricultural information. The higher the educational level of farmers, the more they are willing to use provided information (Miwanda, 2014). Likewise, Assefa (2016) have reported positive and significant relationship of education with access of agricultural information.

Social participation: The results of the study revealed that social participation have positive and significant influence on access to dairy information at $5 \%$ level of significance. This implies that the participant farmers are more likely to access dairy information than those who are not participant in social activities. The probable reason is that involvement in social activities or social organization enables the dairy farmers to create linkage to the larger society and would give higher exposure to access a variety of dairy information. In such situations, where interpersonal linkage is stronger, the smallholder farmers have more preference for accessing information through mutual discussions in formal or informal groups.

The model result indicated that all other factors remaining constant, probability of dairy information access of participant household head increases by $39.10 \%$ compared to non-participant household head. This shows that the dairy farmers who have position in different informal and formal institutions are more likely to have access to various types of dairy farming information. The study result in line with the empirical finding of Mama (2010) revealed that, Group membership provides a social forum where farmers share experience and exchange information in innovation in the farming community.

Extension Contact: The results of the study revealed that extension contact has positive and significant influence on dairy information access at 5\% significance level and accounted for about $1.30 \%$ of the variation. This implies that farmers who had extension contact with development agents had more access to dairy information. In the study area development agents are the predominant sources of dairy information. During group discussion, the participants explained that development agents were providing dairy information related to dairy farming such as efficient milking technique, dairy farm management, insemination, diseases management, adoption of technology and other concerned issue of dairy production. The time of contact with extension agents will increase farmer's knowledge (Getu, 2009).

Access to credit: The model output reveals that access to credit is significant and has a positive impact on the dependent variable at $5 \%$ level of significance. This implies that the farmers who had credit access were more likely to access dairy agricultural information of dairy than those who did not have access to credit. The model result indicated that all other factors remaining constant, probability of dairy information access of the household head that had access to credit increases by $36.46 \%$ compared to the household head who had no access to credit. This study is in agreement with the research findings of Daniel (2008) reported positive and significant relationship of credit access with access and utilization of agricultural information.

Innovation proneness: The model result displayed that this variable was found to have a positive and a significance influence on access of dairy farming information at $10 \%$ level of significance. The marginal effect of the model showed that holding other variables held constant, One unit increment in proneness to innovation would bring about $4.52 \%$ increments in the accessing dairy information. The implication of the result was that the household heads with such behavior access dairy information due to their tendencies to quickly accepting ideas than household head that are laggard in innovation proneness. The result of this study goes along with the findings of Asres (2005) that show the positive and significant relationship of innovation proneness with access to reproductive, productive and community role information of women.

\section{Conclusion and Recommendation}

The finding of this study revealed that education level of household heads was found to influence positively households to access dairy information. This shows that education level of farmers has a role to increase the ability to obtain dairy related information in a better way. The result also indicate that age of household head has a negative effect on the probability a household to access agricultural information of dairy and signifying that Young farmers have more probability to get dairy knowledge and information than older in the area. Therefore, emphasis has to be given towards strengthening rural education at different levels for youth and adults.

Sex of household head was positively and significantly related with dairy information access in favor of male headed households indicating that being female headed might mean having low dairy information access, poor access to in Participation in training and social practice. Hence, before disseminating dairy information Gender difference ought to be considered in order to ensure equal accessibility of agricultural information regarding dairy. 
Findings of this study also indicated that Extension contact has positive and significant relationship with access of dairy information. This implies that the smallholder dairy farmers that have more extension contact with extension workers have better to access agricultural information of dairy than others. Thus, the planning systems should be inclusive and participatory to solve complex problems related to access dairy information that happen due to lack of frequent contact with extension service delivery and encouraging the farmers and development agents to have a regular discussion program.

The finding shows that there was positive and significant relationship of credit access with access of dairy information. Access to credit is important to access information that can solve financial problem of farmers and create opportunity to get agricultural training. In this regard, it is recommended that the agricultural office needs to work cooperatively with financial organizations to facilitate credit service for farmers.

\section{REFRENCE}

Adekunle, A.A., J. Ellis-Jones, I. Ajibefun, R.A. Nyikal, S. Bangali, O. Fatunbi and A. Ange. 2012. Agricultural Innovation in Sub- Saharan Africa: Experiences. FromMultiple-Stakeholder Approaches. Accra, Ghana: Forum for Agricultural Research in Africa.

Amemiya, T. 1981. Qualitative Response Models:A Survey. Journal of Economic Literature. 19: 4.

Asres, E. 2005. Access and Utilization of Development Communication by Rural Women in Dire Dawa Administrative Council, Eastern Ethiopia. Unpublished MSc. Thesis, haramaya University, Haramaya, Ethiopia.

Assefa Million .2016. Access to and utilization of agricultural information by smallholder coffee farmers in deder district, eastern harangue zone, Oromia national regional state. Thesis, haramaya University, Haramaya, Ethiopia.

Babu, S.C., glendenning, C.J., asenso-okyere, k. and govindarajan, S.K. 2012. Farmers' Information Needs and Search Behaviors. IFPRI Discussion Paper 01165.

Bekele Mola. 2008. Information Sharing and Utilization among Farmers: The case of maize The Case of Maize Package in Mettu Woreda, Ormia Region. MSc. Thesis, Haramaya University, Haramaya, Ethiopia.

Central Statistical Agency (CSA). 2013. Agricultural Sample Survey 2012/13. Volume II.Report on Livestock And Livestock Characteristics (Private Peasant Holdings) Federal Democratic Republic of Ethiopia Central Statistical Agency (CSA).

Central Statistical Agency (CSA). 2015. Agricultural Sample Survey 2014/15 Vol.2. Report On Livestock and Livestock Characteristics.

Daniel Tadesse. 2008. Access and utilization of agricultural information by resettler farming households: The case of Metema Woreda, North Gondar, Ethiopia. Msc. Thesis, Haramaya University, Haramaya, Ethiopia.

Geleta, D. 2015.Econometric investigation of farm households' access to agricultural information: the case of maize farmers in dale woreda.International Journal of Recent Scientific Research. Available Online athttp://www.recentscientific.com

Getou Shiferaw. 2009. Factors affecting Adoption of Rainwater Harvesting: The case of Damot Woide Woreda, Southern Nations, Nationalities and Peoples ${ }^{e e}$ Regional State, Ethiopia.

Gujarati, D.N.1995. Basic Econometrics, M.C. Graw Printing Press, U.S.A.

Habtemariam Abate. 2004. The comparative influence of intervening variables in the adoption behavior of maize and dairy farmers in Shashemene and Debre Zeit, Ethiopia. Ph. D. Thesis, University of Pretoria, Pretoria, $294 \mathrm{p}$.

Katungi, E. 2006. Gender, Social Capital and Information Exchange in Rural Uganda IFPRI and Melinda Smale, IFPRI CAPRi Working Paper (59), University of Pretoria.Uganda. accessed on Feb 11, 2017 from: $<$ http://www.capri.cgiar.org/pdf/capriwp59.pdf> .

Madala, P.B. 1983. Logit analysis of technology utilization by rice farmers in DhanushaDistrct, Nepal, Research Paper series.No.22 A/D/C-APROSC, Kathmandu, Nepal.

Mama, J. K. 2010.Access and Utilization of Agricultural Knowledge, and Information by Women Dairy Farmers: The Case of Ada'a District, Oromia Regional State. MSc. Thesis, Haramaya University, Haramaya, Ethiopia.

Miwanda, A., Kabaale, E. and Mayoka, G. 2014. Using ICTs to disseminate Agricultural Marketing Information to Small Scale Rural Farmers in Western Uganda. Makerere University.International Journal of Innovative and Applied Research, Volume 2.

Oladele, I.O. 2011. Information Seeking and Utilization among Agricultural Researchers in Nigeria. Proceedings of the Third Asian Conference for Information Technology in Agriculture,Beijing,China.

Pindyck, R. and Rubinfeld, C. 1981.Econometric Models and Econometric Forecasts. Second Edition.McGrawHill book Co. NewYork.

Rehman, S., Muhammad, I., Ashraf, K., Mahmood, C. and Bibi, I. 2013. Effect of farmers' socioeconomic characteristics on access toagricultural information: empirical evidence from Pakistan.The Journal of Animal 
and Plant Sciences, 23(1) Page: 324-32

Yilma, Z., Desta, H. and Mugisha, A. 2011. Innovations, Actors and Linkages in the Ethiopian Dairy Value Chain. Food and Agriculture Organization of the United Nations, Sub-Regional Office for Eastern Africa. 34-56 p. Zijlstra, J., Berhanu T., Vernooij, A., Boere, A. and der Lee, J.2015. Business Opportunities Report Dairy \#2 in the series written for the "Ethiopian Netherlands business event 5-6. 